\title{
La Alianza del Pacífico como actor regional: factores de éxito para la cohesión regional hacia la proyección internacional
}

\author{
Catherine Ortiz MORALES*
}

Archivo recibido: 19 de mayo de 2016

Archivo aprobado: 14 de noviembre de 2016

Doi: http://10.12804/revistas.urosario.edu.co/desafios/a.4885

Para citar este artículo: Ortiz Morales, C. (2017). La Alianza del Pacífico como actor regional: factores de éxito para la cohesión regional hacia la proyección internacional. Desafíos, 29(1), 49-77. Doi: http://10.12804/revistas.urosario.edu.co/desafios/a.4885

\section{Resumen}

Este articulo analiza la cohesión regional de la Alianza del Pacifico para su consolidación como actor regional. A partir de su creación con la firma del Acuerdo Marco (2012), inicia el proceso de objeto pasivo a sujeto activo, de acuerdo con los niveles de regionalidad, siendo la Alianza del Pacifico un proyecto embrionario que busca responder a los retos de la globalización para una proyección mancomunada de sus paises miembros y servir de plataforma de inserción internacional. Sin embargo, su consolidación como actor regional dentro del orden latinoamericano enfrenta grandes desafíos dadas sus debilidades y fortalezas en materia de liderazgo, interdependencia, convergencia, identidad e institucionalidad como factores de éxito para la cohesión regional que catapulte potencialidades frente a las oportunidades y amenazas del sistema internacional. Palabras clave: Integración regional, actor regional, cobesión, Alianza del Pacífico.

\footnotetext{
* Docente e investigadora de la Universidad de San Buenaventura, Bogotá. Facultad de Ciencias Jurídicas y Políticas. Correo electrónico: jeortiz@usbbog.edu.co. ORCID: http:// orcid.org/0000-0001-9563-3115
} 


\title{
The Pacific Alliance as a Regional Actor: Success Factors for Regional Cohesion Towards International Integration
}

\begin{abstract}
This article analyzes the cohesion of the Pacific Alliance in terms of its consolidation as a regionalplayer. From its creation with the signing of the Framework. Agreement in 2012, the formative process starts from a passive object to an active subject according to the levels of regionality. The Pacific Alliance is considered as an embryonic project that seeks to respond to the challenges of globalization towards the common projection of its member-states and platform for their international insertion. However, its consolidation as a regional player in Latin America faces major challenges given the weaknesses and strengths in leadership, interdependence, convergence, identity and institutions as success factors for regional cohesion in order to pool member-states' potentials for opportunities and against threats in the international system.
\end{abstract}

Keywords: Regional integration, regional actor, cohesion, Pacific Alliance.

\section{AAliança do Pacífico como ator regional: fatores de sucesso para a coesão regional à projeção internacional}

\begin{abstract}
Resumo
Este artigo analisa a coesão regional da Aliança do Pacífico para a sua consolidação como ator regional. A partir da sua criação com a assinatura do Acordo Marco (2012), inicia o processo de objeto passivo a sujeito ativo, de acordo com os niveis de regionalidade, sendo a Aliança do Pacífico um projeto embrionário que busca responder aos desafios da globalização para uma projeção mancomunada dos seus países membros e servir de plataforma de inserção internacional. No entanto, a sua consolidação como ator regional dentro da ordem latino-americana enfrenta grandes desafios devido às suas debilidades e fortalezas em matéria de liderança, interdependência, convergência, identidade e institucionalidade como fatores de sucesso para a coesão regional que catapulte potencialidades frente às oportunidades e ameaças do sistema internacional.
\end{abstract}

Palavras-chave: Fatores de sucesso, ator regional, integração, Aliança do Pacífico. 


\section{Introducción}

En el marco de los procesos subregionales de concertación, cooperación e integración regional, surge la Alianza del Pacífico como un nuevo actor regional en la configuración del orden latinoamericano. Sin embargo, la unidad y cohesión regional ha sido un reto para catapultar una proyección internacional mancomunada de la región latinoamericana, a partir de las distintas perspectivas latinoamericanas existentes de heterogeneidad y fragmentación regional, y de la dualidad y dicotomía de abordar las relaciones internacionales latinoamericanas dentro del espectro de un mínimo común denominador que abarca Estados Unidos o Latinoamérica, estableciéndose esquemas defensivos como estrategia política.

En primera medida, ¿qué se entiende por cohesión regional? De acuerdo con el Diccionario de la Real Academia Española (RAE), la cohesión es la acción y efecto de reunirse o adherirse las cosas entre sí. En sociología, se hace referencia a la cohesión social en términos de pertenencia y consenso entre los integrantes de una comunidad que define intereses y necesidades comunes. En este marco de una definición básica y en términos de integración regional, Bartesaghi y Pereira (2016) en el artículo "La cohesión regional en los procesos de integración en América Latina y el Caribe” plantean la institucionalidad y la cohesión como factores de éxito en los procesos de integración.

La Alianza del Pacífico es un esquema de cooperación económico embrionario que nace a partir de la firma del Acuerdo Marco (2012), que entra en vigor en 2015. Su realidad se encuentra determinada por a) falta de liderazgo; b) bajos niveles de interdependencia económica; c) convergencia regional dada por la afinidad política que frente a la configuración del orden regional genera un mínimo común denominador ante el aislamiento y distanciamiento de las partes de la escena regional, d) falta de una identidad estatal obstaculizada por los problemas domésticos, pero con interés de consolidar un actor con identidad regional dentro de una región heterogénea en construcción, y e) bajos niveles de institucionalidad dependiente de la voluntad 
política de los gobiernos, para una respuesta mancomunada frente a las externalidades del sistema internacional.

El presente artículo plantea como pregunta de investigación, ¿`uáles son los factores determinantes de cohesión regional de la Alianza del Pacífico para una proyección internacional mancomunada? Así, se busca analizar la cohesión regional de la Alianza del Pacífico para una proyección mancomunada. El argumento central de este artículo establece que la Alianza del Pacífico en su proceso de consolidación como actor regional dentro del orden latinoamericano para una proyección internacional, enfrenta grandes debilidades y fortalezas en materia de liderazgo, interdependencia, convergencia, identidad e institucionalidad, como factores de éxito para la cohesión regional que catapulte potencialidades como plataforma de inserción frente a las oportunidades y amenazas del sistema internacional.

Para el análisis se formula un modelo de cohesión regional a partir de un enfoque ecléctico, que reúne categorías de análisis de las distintas teorías de Relaciones Internacionales, para determinar y justificar los factores de éxito en cada nivel de regionalidad planteados por la Teoría del Nuevo Regionalismo propuesto por Hettne (2002). Así, en la primera parte se busca plantear el modelo de análisis de cohesión regional y sus factores de éxito (categorías de análisis) para posteriormente aplicar en el caso de la Alianza del Pacífico y su consolidación como actor regional hacia la proyección internacional.

\section{Modelo de análisis de cohesión regional: factores de éxito para la integración latinoamericana}

Dentro de las dinámicas de la globalización surgen las iniciativas de integración como resultado del regionalismo y la regionalización. El regionalismo es entendido como el proyecto político que engloba las iniciativas políticas de representantes gubernamentales, con el fin de estrechar la cooperación política y económica entre Estados y actores de una misma región. En cuanto a la regionalización, esta se entiende como los procesos de integración en los cuales subyacen tanto inte- 
reses económicos como elementos ideológico-culturales que se dan de forma efectiva en el interior de uno o varios ámbitos geográficos regionales, por la intensidad de las interacciones sociales y especialmente económicas (Ibañez, 2000). Las iniciativas de integración regional tiene diferentes alcances y objetivos desde la concertación política y económica, pasando por la cooperación, hasta auténticos procesos de integración (Arenal, 2001).

La concertación hace referencia al mecanismo mediante el cual dos gobiernos actúan conjuntamente en el terreno estatal, generalmente a nivel diplomático y con fines de preferencia políticos. La cooperación es el esquema por medio del cual el estado, con participación activa del sector empresarial, produce proyectos y acuerdos de tipo económico y comercial con trasfondo político. Por último, la integración es un proceso más amplio, complejo y profundo entre dos o más naciones, que implica una vinculación e interdependencia social, política, económica, cultural, científica, diplomática o incluso militar con la participación de variados agentes de sociedades involucradas (Tokatlian, 1994).

Dentro de este marco y a partir del papel de lo regional, para el nuevo regionalismo la integración regional hace referencia a la interacción organizada, económica o política, entre unidades antes autónomas; por su parte, la cooperación regional hace referencia a actividades intergubernamentales que tiene como fin lograr la integración; por último, el regionalismo se entiende como la ideología y proyecto político de la construcción de la región (Hettne, 2002); es decir, en términos de los componentes políticos de la integración (Tokatlian, 1994) es un proceso de concertación política.

El nuevo regionalismo resalta el retorno a lo político dado que busca dar relevancia al vínculo con la globalización cuestionando si este es una parte integral de la globalización o si surge como reacción contra esta (Serrano, 2008). En este contexto, y dentro del papel de lo regional en el nuevo orden mundial, la Teoría del Nuevo Regionalismo plantea que el proceso de regionalización se da en términos de niveles de "regionalidad", es decir, el proceso mediante el cual un 
área geográfica pasa de un objeto pasivo a un sujeto activo, capaz de articular los intereses transnacionales de la región emergente (Hettne \& Söderbaum, 2000).

La regionalidad como proyecto político comprende cinco etapas en su formación: a) un espacio regional, que es una zona geográfica delimitada; b) un complejo regional dado por las relaciones de interdependencia y de la estabilidad general del sistema regional; c) una sociedad regional, espontánea y organizada ya sea en el ámbito cultural, económico, político o militar, denominado en una región formal o región "real"; d) una comunidad regional que tiene lugar a partir de un marco organizativo durable (formal o informal), con el objetivo de propiciar y promover una comunicación social y la convergencia de valores y acciones, entre otros ámbitos como los regímenes políticos, las políticas económicas y los acuerdos sobre seguridad, creándose una sociedad civil transnacional y e) un sistema regional institucionalizado con una estructura para la toma de decisiones y una capacidad como actor más sólido (Hettne, 2002).

Con base en los niveles anteriores y teniéndose en cuenta las distintas teorías de las Relaciones Internacionales, se determinan y justifican las categorías de análisis dentro de cada nivel de regionalidad expuesto inicialmente.

\section{Categorías de análisis}

Liderazgo. Dentro del nivel espacio-regional, cabe señalarse que para el Realismo se basa en entender que la anarquía es compatible con cierto orden, es decir, el escenario internacional es anárquico y competitivo, y el estado es el actor exclusivo, racional y unitario, cuya finalidad es maximizar el poder para defender su interés nacional y propender por el balance del poder (Frasson-Quenoz, 2015). En este contexto, para la tradición Realista, el regionalismo busca “( ...) aglutinar los estados más importantes de una misma región y formar con ellos grupos con mayor o menor cohesión bajo el liderazgo de un Estado regionalmente hegemónico (...)" (Camargo, 2000, p. 72). 
La regionalización favorece la emergencia de potencias regionales, pero también promueve conflictos por el liderazgo regional o subregional (Nolte, 2006). Las potencias regionales son: a) estados que pertenecen a la región considerada; b) muestran una superioridad en términos de capacidades de poder, es decir, poseen la mayor cuota de poder en la región y c) ejercen algún tipo de influencia en la región (Destradi, 2010, p. 905). Por otra parte, las estrategias adoptadas por las potencias regionales con los estados vecinos se centran en la formación del orden regional combinando liderazgo y poder, sobre los recursos que desde su posición de liderazgo proporcionan bienes públicos. Para ejercer el liderazgo, el líder de un grupo de estados busca realizar o facilitar la realización de sus objetivos comunes (Destradi, 2010, p. 921).

Así, las potencias regionales se sustentan en ser "un poder líder (leading power) en la región (= potencia regional), que se define a base de sus recursos de poder y su autopercepción, y un liderazgo (leadership), lo que se refiere a la influencia política en foros diplomáticos" (Nolte, 2006, p. 15). Las potencias regionales combinan recursos de poder (hard power y soft power) con la autodefinición del papel en la política internacional y la percepción externa de ese papel, para lo cual, “(...) tiene la pretensión de un liderazgo en la región (voluntad, rol y percepción) [y su] (...) liderazgo regional es reconocido o al menos respetado por otros países en la región y fuera de la región - especialmente por las otras potencias regionales (aceptación)” (Nolte, 2006, p. 18).

Desde los aportes teóricos latinoamericanos, la noción de poder desde el enfoque realista fue reemplazo por el concepto de autonomía. Así, los propósitos de una acción internacional autónoma son muy distintos del ejercicio de poder, como señala Tickner (2002) referenciando a Jaguaribe (1979):

Mientras el poder sirve para influir en las acciones de otros actores de acuerdo con los intereses de un actor en particular (Morgenthau, 1968), la autonomía provee los medios para defender diversos intereses nacionales frente a las potencias dominantes en el sistema internacional. Más importante aún, la autonomía 
ofrece una medición de la viabilidad nacional, entendida como la capacidad del estado de ejercer sus funciones políticas, económicas, militares y culturales (p. 112).

Interdependencia. Dentro del segundo nivel de regionalidad, la interdependencia se caracteriza por la existencia de canales múltiples que conectan a las sociedades, así como por los costos recíprocos en el intercambio que supone un beneficio pero también, un costo (Keohane \& Nye, 1977); es a partir de la interdependencia que surge una región real. Para el Intergubernamentalismo Liberal, la integración surge como resultado de la interdependencia económica en torno a recursos estratégicos; por ejemplo, en el caso de la Unión Europea el carbón y el acero (Moravcsik, 1998).

El Neoliberalismo señala que respecto a la naturaleza del sistema internacional se genera un patrón de interdependencia entre las preferencias estatales (interdependencia política) que da forma al comportamiento del Estado y que impone costos y beneficios sobre otros (externalidades) (Moravcsik, 2008). Por lo anterior, la integración genera mayor interdependencia en términos económicos, políticos y sociales entre las partes, determinado según el alcance, el modelo de desarrollo e inserción internacional en pro de la cohesión regional.

Para los enfoques latinoamericanos existe una relación entre la interdependencia y la dependencia como productos de las transformaciones ocurridas en la economía mundial (principalmente la transnacionalización y la globalización), en la cual:

[...] la noción de interdependencia fue utilizada, [...], como un instrumento retórico diseñado para disfrazar la naturaleza asimétrica de las relaciones internacionales entre el centro y la periferia, y para insinuar que los intereses mutuos quedarían mejor servidos mediante un comercio más vigoroso y la existencia de economías abiertas (Tickner, 2002, pp. 116-117).

Convergencia. La configuración de una sociedad regional surge a partir de la convergencia de intereses políticos y económicos, la cual 
permite que la región se organice ya sea en el ámbito cultural, económico, político o militar, configurando una región formal. Desde un enfoque económico, la convergencia y divergencia regional se basa en modelos teóricos de crecimiento a partir de los cuales, se entiende que “ (...) las diferencias en niveles de bienestar y riqueza existentes entre países tienden a disminuir o desaparecer, convergencia, o si, por el contrario, tienden a persistir o aumentar, divergencia" (Cuervo, 2004, p. 30).

Para la Teoría de Convergencia Regional, la realidad sudamericana se encuentra caracterizada por la existencia de numerosos esquemas de integración regional que compiten entre sí, por lo que es necesaria la convergencia en torno a un mínimo común denominador alrededor de tres preguntas fundamentales que han caracterizado históricamente los intentos de regionalismo para alcanzar la cohesión regional: a) la relación con la potencia líder en el plano internacional; b) el papel que juega el líder regional o paymaster, y c) el modelo económico y de desarrollo que debe ser adoptado (Gardini, 2010).

Identidad. Dentro de una comunidad regional es necesario resaltar que el regionalismo contempla las ideas, identidades e ideologías relacionadas con un proyecto regional dirigido por los Estados (Söderbaum, 2003). Por lo anterior, no se debe desconocer que:

el tema de identidad y el sentimiento de "pertenencia" están presentes en algunos procesos regionales, lo que, si por un lado puede constituir un elemento de mayor cohesión, por otro puede resultar en una mayor incomprensión y dificultad de aceptación del "otro", creándose bolsones de discriminación y de exclusión en el propio espacio regionalizado (Camargo, 2000, p. 73).

La transformación de la conducta internacional de los estados está determinada por los cambios en las imágenes de los mismos, los cuales son sujetos sociales que desarrollan un auto concepto sobre el cual reaccionan al ambiente internacional. En este sentido, las decisiones de los líderes políticos en materia internacional están determinadas por los significados que los estados atribuyen a los objetos sociales 
y por las propias imágenes que tienen de sí mismos, es decir, por la autoimagen que ellos mismos construyen y que contiene elementos básicos que determinan el núcleo central de la personalidad colectiva (Estado) (Kiselev \& Smirnova, 2004).

Así, la autoimagen del estado es el conjunto de creencias colectivas sobre sí mismos, resultado de la intersubjetividad y del diálogo de los actores en las Relaciones Internacionales, que se ve reflejada en los discursos de los líderes políticos. Un enfoque para el análisis de la autoimagen comprende tres componentes: a) la identidad; b) la posición, y c) el rol. La identidad constituye el núcleo central de la autoimagen y proporciona continuidad y consistencia entre el liderazgo político a partir de las ideas y valores compartidos. La posición refleja la situación de un país en el sistema internacional y se relaciona no solo con la autoestima, sino con la valoración que los demás hacen de él. Por último, el papel o imagen situacional está representado por los roles que marcan la conducta internacional de un estado (Kiselev \& Smirnova, 2004).

A partir del supuesto del constructivismo, en el que la vida internacional es social (en contraposición a material solamente) y construida (a diferencia de pre dado), los estados se crean el uno al otro como enemigos, rivales o socios, compartiendo interpretaciones de sus identidades respectivas y actuando de acuerdo con las expectativas del otro (Kubálková, 2001). Las formaciones discursivas contienen las identidades, que junto con las prácticas sociales cotidianas, constituyen la estructura cognitiva social. La identidad social establece un conjunto de descripciones para vivir y actuar, ayudando en la comprensión de cómo el estado comprende otros estados. Las identidades simplifican y homogenizan en términos de la identidad del Yo, categorizando de acuerdo con la necesidad de entender, asignando una identidad con prácticas discursivas asociadas y atribuyéndole intenciones y motivos (Hopf, 2002). 
Institucionalidad. Como los institucionalistas neoliberales subrayan, en cuanto al sistema regional institucionalizado es importante el papel de las instituciones y organizaciones regionales para la gestión de las interdependencias y la consecución de bienes colectivos a nivel regional, así como su influencia (Söderbaum, 2003). Por esto, es importante señalar que el rol de las instituciones es coordinar las políticas nacionales sobre la base de principios generales, a) prescribir papeles de conducta; b) restringir la actividad, y d) configurar las expectativas (Keohane, 1993).

Con base en lo anterior, se puede establecer la distinción conceptual entre regionalismo y multilateralismo, dado que este último hace referencia a la coordinación de las relaciones entre tres o más estados (dimensión cuantitativa) de acuerdo con principios generales de conducta (dimensión cualitativa: coordina el comportamiento) en una forma institucional internacional (instituciones) de gran exigencia (Ruggie, 1998).

Figura 1. Modelo de análisis de cohesión regional y sus factores de éxito

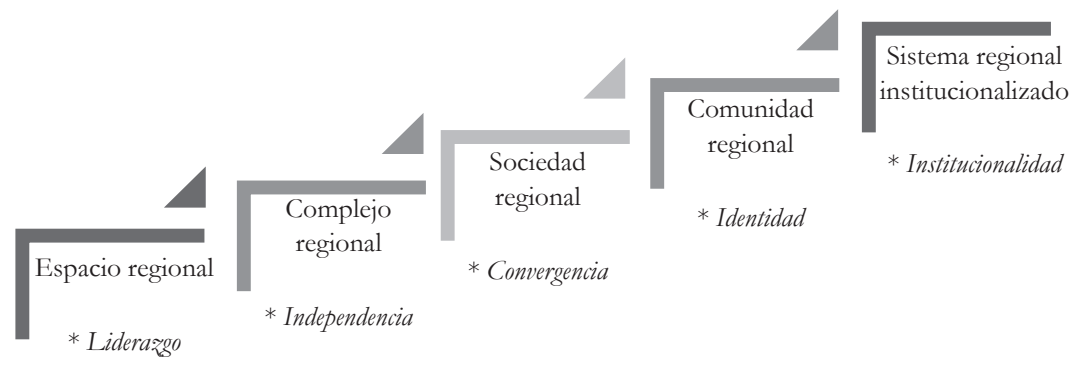

Fuente: Hettne, 2002.

Nota: el modelo de análisis de cohesión regional y los factores de éxito para los procesos de integración son determinados de acuerdo a los niveles de regionalidad propuestos por la Teoría del Nuevo Regionalismo

En conclusión, a partir de los niveles de regionalidad presentados por la Teoría del Nuevo Regionalismo, el modelo de análisis de cohesión regional propuesto en este artículo (figura 1) parte de establecer cinco factores de éxito dadas las cinco categorías de análisis planteadas en cada uno: liderazgo, interdependencia, convergencia, identidad e institucionalidad. 


\section{La Alianza del Pacífico y la cohesión regional: hacia la configuración de un actor regional con proyección internacional}

Desde las tres realidades sociales que coexisten en la sociedad internacional (el sistema político-diplomático, el sistema transnacional y la sociedad humana), el sistema político-diplomático, conformado por los estados y organizaciones internacionales, tiene lugar por las relaciones que se producen entre diferentes unidades políticas que actúan internacionalmente en tanto detentadoras de los poderes públicos, de la expresión de las voluntades y las aspiraciones de los individuos y de los grupos que las componen, generando la existencia de normas e instituciones comunes. Así, el sistema interestatal juega un papel fundamental en la conformación de las principales estructuras y dinámicas de la sociedad internacional, interpretada en términos de relaciones entre Estados, generando la existencia de normas e instituciones comunes (Arenal, 2005). Es en este marco de relaciones se toma a la Alianza del Pacífico con el propósito de analizar su consolidación como actor regional a partir de la cohesión regional y los factores de éxito planteados en cada nivel de regionalidad.

\subsection{La Alianza del Pacífico y su cohesión regional: debilidades y fortalezas}

Liderazgo. En términos de capacidades de poder, la Alianza del Pacífico cuenta con una clara potencia regional latinoamericana: México. De igual manera, dentro de la configuración del orden regional, y teniendo en cuenta las capacidades de Estados menores, Colombia y Chile han sido catalogados como potencias regionales secundarias. Sin embargo,, México enfrenta grandes problemas en temas de seguridad que limitan su proyección en el escenario latinoamericano, conllevando a la pérdida de legitimidad, a pesar de su gran influencia cultural y económica (Torres del Sel, 2013).

México se caracteriza por sus múltiples pertenencias hacia Norteamérica, Centroamérica y el Caribe. De igual manera, por su pertenencia al grupo de economías de gran importancia en el sistema 
internacional, como lo es el G20 (Villamar, 2013). No obstante, su proyección internacional, en cierto modo, se ha visto limitada por su cercanía geográfica con la primera potencia del mundo, así como por el hecho de ser un país latinoamericano en términos culturales e históricos (Torres del Sel, 2013). Esta realidad ha hecho que su rol como potencia regional se encuentre determinado a enfrentar una posición geopolítica dual, que le ha dificultado integrar en una visión de conjunto los dos vértices del triángulo (González, 2008).

En la jerarquía de poder regional, Colombia y Chile han sido catalogados como potencias regionales secundarias por ser países medianos; en el primer caso naciente y en el segundo caso maduro. Colombia, durante los ocho años de la administración del Presidente Álvaro Uribe, atravesó por una situación de aislamiento por las distintas crisis diplomáticas con sus vecinos, la bilateralización y el acoplamiento hacia Estados Unidos, la pasividad de su política exterior y el conflicto interno, entre otros problemas (Ardila, 2012). Chile se ha caracterizado por sus elementos tangibles como población, recursos naturales y capacidad industrial y agrícola, fuerza militar y territorio, así como por sus elementos intangibles en términos de la calidad de liderato, la eficiencia burocrática, calidad de la diplomacia y apoyo exterior por medio de alianzas (Artaza Rouxel, 2012).

$\mathrm{Al}$ inicio del siglo XXI, Colombia y Chile estuvieron ausentes en la configuración del orden latinoamericano. Como ya se mencionó, Colombia enfrentó un aislamiento regional a partir de la desconfianza generada por su cercanía con los Estados Unidos y la securitización de su política exterior. A su vez, Chile enfrentó un distanciamiento de la escena latinoamericana iniciada a partir de su retiro de la Comunidad Andina en 1972 y su apuesta desde entonces por un modelo de diversificación de relaciones económico-comerciales con otras áreas geográficas, especialmente con Asía-Pacífico. Dada la estrategia chilena en su apuesta por el Regionalismo Abierto como modelo de desarrollo e inserción internacional, se centró en la firma de tratados de libre comercio con distintas áreas geográficas, fortaleciendo cierta autonomía a partir de la diversificación de sus relaciones y al 
no depender de un único y exclusivo referente de poder en un marco de relacionamiento caracterizado por el acoplamiento. ${ }^{1}$

Pese a las asimetrías de poder, los países miembros de la Alianza del Pacífico, más allá de la intensión de crear un nuevo asociacionismo dentro del ajedrez latinoamericano, parten de sus intereses para la configuración del orden regional. Así, dentro del mismo, para la primera década del siglo XXI que se determinó por "el giro a la izquierda", surgió el proyecto de sudamericanización del Brasil con la UNASUR y el proyecto ALBA abanderado por Venezuela; estrategias de influencia subregionales en contraposición y exclusión de México. Sin embargo, dentro de la Alianza del Pacífico, ninguna de las partes transciende sus intereses hacia la pretensión de un liderazgo que asuma de manera directa los costos de la integración (paymaster) dadas las situaciones internas de cada uno sus miembros.

De esta manera, dentro de la Alianza del Pacífico, más que caracterizarse en una relación vertical de poder como la planteada por el Realismo, la pretensión de liderazgo se limita al consenso en términos de cooperación económica hacia la inserción internacional, especialmente hacía Asía-Pacífico. Así como dentro del orden regional, un rol más activo de los países miembros mediante un "liderazgo pragmático" para la configuración del orden regional dado los interese de convergencia entre Mercosur y Alianza del Pacífico, para aumentar el poder negociador con las debilidades presentes en términos de viabilidad nacional frente a las actuales dinámicas de un orden multipolar y su permisibilidad internacional. $^{2}$

Interdependencia. Dentro de los perfiles comerciales de los países miembros de la Alianza del Pacífico, los principales mercados son potencias extranjeras. En ese sentido, para México, Colombia, Perú

\footnotetext{
1 Las características de los modelos de política exterior son planteados por Tokatlian \& Rusell (2009).

2 De acuerdo con los aportes latinoamericanos de la Teoría de la Autonomía, la viabilidad nacional hace referencia a los recursos humanos y materiales del que disponen los estados. La permisibilidad internacional hace referencia a las condiciones y capacidades para neutralizar el riesgo proveniente de terceros (Jaguaribe, 1979).
} 
y Chile, los principales socios comerciales para 2012 fueron Estados Unidos, la Unión Europea y China (OMC, 2013); de igual manera, la realidad de las relaciones comerciales entre los miembros denota la baja complementariedad de sus economías y la baja intensidad de sus relaciones comerciales.

Como se establece en la tabla 1, para 2012, año de la firma del Acuerdo Marco, la interdependencia económica - producto de las relaciones comerciales y reflejada en la balanza comercial- representaba en todos los casos menos de un 10\%. En términos de exportación, la menor participación dentro de la Alianza del Pacífico hacia los demás países miembros fue de México con un flujo de USD 9.372 millones, que equivale al 2.5\% del total de sus exportaciones al mundo. Perú cuenta con una mayor participación de sus exportaciones hacia sus socios de la alianza, con un $7.4 \%$ que equivale a USD 3.377 millones de sus USD 45.639 millones de sus exportaciones totales, a pesar de ser la economía más pequeña entre sus socios.

En cuanto a las importaciones, el principal miembro que importa de sus socios de la alianza es Colombia con USD 7.456 millones, es decir, un $12 \%$ de sus importaciones totales, que son de USD 59.111 millones. La economía mexicana, que es la más grande de los cuatro socios, tan solo importa de ellos el 0,74\% que equivale a USD 2.819 millones del total de sus importaciones de USD 380.477 millones. Continuando con el análisis de la tabla 1, es claro que la interdependencia económica de sus miembros es de baja intensidad para el año en el que surge la Alianza del Pacífico, lo que representa una debilidad que no permite hablar de una región real más que formal; sin embargo, esta realidad estructural de acuerdo a los intereses de las partes puede convertirse en una oportunidad que, de no desconocer los retos económicos, productivos y comerciales de cada una de las economías nacionales, permitan direccionar los esfuerzos hacia el establecimiento de cadenas de valor y ventajas competitivas para una mejor inserción internacional mancomunadamente, especialmente hacia Asia Pacífico. 
Tabla 1. Interdependencia económica de los miembros de la Alianza del Pacífico.

\begin{tabular}{|c|c|c|c|c|c|c|c|}
\hline $\begin{array}{l}O_{0}^{\infty} \\
\sum_{i=1}^{\infty} \\
\sum \\
\sum\end{array}$ & 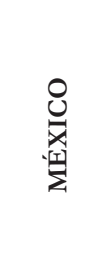 & $\begin{array}{l}\overleftarrow{1} \\
\sum_{0}^{\circ} \\
0 \\
0 \\
0\end{array}$ & 兑 & 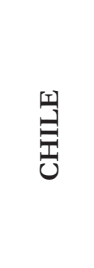 & 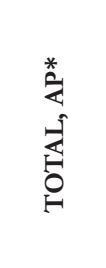 & 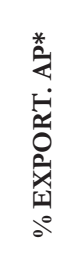 & 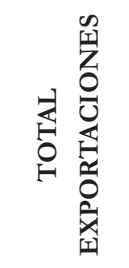 \\
\hline MÉXICO & & 5.592 & 1.527 & 2.251 & 9.372 & $2.5 \%$ & 370.827 \\
\hline COLOMBIA & 877 & & 1.135 & 2.177 & 4.190 & $6.9 \%$ & 60.274 \\
\hline PERÚ & 439 & 910 & & 2.027 & 3.377 & $7.4 \%$ & 45.639 \\
\hline CHILE & 1.502 & 952 & 1.014 & & 3.469 & $4.4 \%$ & 78.277 \\
\hline \multirow{2}{*}{ TOTAL AP* } & \multirow{2}{*}{2.819} & \multirow{2}{*}{7.456} & \multirow{2}{*}{3.676} & \multirow{2}{*}{6.456} & 20.409 & \multirow{2}{*}{$3.6 \%$} & \multirow{2}{*}{555.017} \\
\hline & & & & & 20.407 & & \\
\hline \% IMPORT. AP* & $0.74 \%$ & $12.6 \%$ & $8.6 \%$ & $8.1 \%$ & $2.5 \%$ & \multirow{2}{*}{\multicolumn{2}{|c|}{$\begin{array}{c}\text { Valores en millones } \\
\text { de USD } \\
2012\end{array}$}} \\
\hline $\begin{array}{c}\text { TOTAL } \\
\text { IMPORTACIONES }\end{array}$ & 380.477 & 59.111 & 42.545 & 79.468 & 561.601 & & \\
\hline
\end{tabular}

* AP hace referencia a la Alianza del Pacífico.

Fuente: elaboración propia a partir de ALADI, 2012 y OMC, 2013.

Convergencia. El común denominador establecido entre las partes de la Alianza del Pacífico para la convergencia regional parte de la configuración del orden político latinoamericano, caracterizado en la primera década del siglo XXI por el giro a la izquierda, la posición de aislamiento, distanciamiento y exclusión de los miembros del orden regional, la pérdida relativa ${ }^{3}$ de centralidad de Estados Unidos para muchos países de América Latina, la crisis de la Comunidad Andina, el cambio del centro de poder mundial del Atlántico al Pacifico, dada la configuración de un nuevo orden mundial a partir de la multidimensionalidad del poder, el surgimiento de esquemas de cooperación sur-sur y las alianzas político-diplomáticas como estrategias de soft balancing, entre otros factores determinantes.

\footnotetext{
3 La afirmación del autor se centra en la distinción respecto a la "perdida" y no "colapso", "relativa" y no "absoluta" (Tokatlian, 2011b).
} 
En el caso de las aproximaciones entre los estados latinoamericanos, la existencia de un mínimo común denominador ha estado determinado por la dualidad y dicotomía de privilegiar las relaciones con Estados Unidos o América Latina, desconociéndose en muchos casos las transformaciones del sistema internacional y las nuevas amenazas dadas con las dinámicas de la globalización. Para Gardini (2010) y su teoría de convergencia regional, los intentos de regionalismo en América Latina han respondido a la convergencia en tres temas de interés, a saber: a) la relación con la potencia líder en el plano internacional, Estados Unidos; b) el papel que juega el líder regional o paymaster, Brasil, y c) el modelo económico y de desarrollo que debe ser adoptado. Lo anterior en el marco de establecer la convergencia en temas claves dentro del sistema interestatal de la dimensión político-diplomática para alcanzar una "unidad regional cohesionada y consolidada" (Gardini, 2010).

En este escenario, el surgimiento y consolidación de la Alianza del Pacífico con la firma del Acuerdo Marco en 2012, constituye la convergencia de los Estados miembros en la dimensión político-diplomática en un mínimo común denominador, analizado a partir de las tres categorías de análisis planteadas por la Teoría de Convergencia Regional para la unidad y cohesión regional.

En cuanto a las relaciones con Estados Unidos, los países miembros de la Alianza del Pacífico se caracterizan por ser casos aproximados al modelo de política exterior de acomodamiento. Este opta por una transformación moderada del orden vigente, observa a Estados Unidos como un amigo, preserva una posición de relativa indiferencia hacia la región y es bastante activo en la búsqueda de mayores vínculos extra-hemisféricos (Tokatlian \& Russell, 2009). En ese sentido, Estados Unidos constituye un importante referente de política exterior más no el único, en su apuesta por la diversificación de relaciones económico-comerciales a través de la estrategia de firmas de TLC como mecanismo de inserción internacional.

Dentro de la jerarquía de poder regional solo dos Estados cuentan con las capacidades para ejercer liderazgo y asumir los costos de la 
integración, dadas sus capacidades y posiciones estructurales: México y Brasil. Sin embargo, frente a las pretensiones regionales de Brasil en América del Sur, existen países que son ambivalentes frente a su proyecto político regional (regionalismo) en el marco de Unasur, viéndolo como una mezcla entre un paymaster y una nueva potencia colonial (Malamud, 2011).

El papel de Brasil se ha visto obstaculizado por sus problemas domésticos, y frente a su pretensión de liderazgo, la Alianza del Pacífico ha sido para México un mecanismo para retornar a la configuración del orden regional ante la exclusión del proyecto sudamericano de Brasil (Soriano, 2012).

Frente a estos líderes regionales, Colombia y Perú se han centrado en establecer una alianza estratégica con Brasil. En cuanto a Chile, ha planteado una convergencia reconociendo que frente a las dinámicas de la globalización se enfrenta un déficit en integración dada la dispersión de iniciativas sin horizonte común hacia la convergencia. Por lo anterior, dentro de su política exterior se ha establecido lograr una mayor unidad, fortalecer la participación de Chile dentro de los distintos mecanismos de integración existente hacia la consolidación como región e impulsar puentes de entendimiento (Bachelet, 2013).

Por ultimo en cuanto al modelo de desarrollo, las partes han adoptado el modelo de regionalismo abierto, constituyéndose la Alianza del Pacífico como el último bastión (Briceño Ruiz, 2013). Esta alianza constituye el espacio de cooperación económica orientado hacia la consolidación de un área de integración profunda; sin embargo, el crecimiento de sus economías se basa en las exportaciones, principalmente de materias primas, enfrentando el reto de la falta de complementariedad y sus bajos niveles de interdependencia económica.

A partir del modelo de regionalismo abierto, se encuentran distinciones entre las partes. México ha privilegiado su relación con los socios del norte en el marco del TLCAN, así como una activa inserción internacional hacia el Asia-Pacífico. Chile ha apostado por una activa estrategia de inserción internacional, que le llevó a distanciarse 
de la región, centrando su perspectiva de integración "como la consecuencia de fenómenos económicos y sociales autónomos de la acción del gobierno en que las fuerzas motoras eran los empresarios o, en menor medida, las regiones del país" (Van Klaveren, 2011, p. 156). En cuanto a Colombia y Perú, su estrategia se ha centrado en favorecer y privilegiar los procesos de integración regional como la Comunidad Andina; sin embargo, con la adopción de la decisión 598 de 2004 del Consejo Andino de Ministros de Relaciones Exteriores de la CAN, se iniciaron los procesos de negociación de manera unilateral con terceros países no miembros de la comunidad, iniciando con Estados Unidos para un TLC.

Identidad. En América Latina, el regionalismo latinoamericano se caracteriza por la diversidad debido a los objetivos, la institucionalización y la participación estatal; el solapamiento frente a la condición de miembro que un mismo Estado puede tener en varias agrupaciones regionales y la doble militancia; el impulso intergubernamental, ya que los procesos de integración han surgido de iniciativas gubernamentales conducidas por las estancias estatales; el protagonismo empresarial con la participación del sector privado en el impulso y desarrollo de las iniciativas; y por ser una estrategia de desarrollo (Ibañez, 2000).

En materia del regionalismo latinoamericano se ha planteado un debate que abarca distintas perspectivas, desde la heterogeneidad hasta la fragmentación. Para Briceño Ruiz (2012, 2013), esta última está presente en el contexto latinoamericano y se encuentra materializada en la existencia de tres ejes con modelos distintos; a) eje de regionalismo abierto-TLCAN, b) eje revisionista, y c) eje anti sistémico. Desde una perspectiva de fragmentación se establece que la misma es una realidad regional, ya que los proyectos no forman círculos concéntricos ni muestran un mínimo común denominador o convergencia, produciendo sub regionalismos que responden a diferentes lógicas (Malamud \& Gardini, 2012).

Desde la perspectiva de la heterogeneidad se hace alusión al concepto de "complejo integracionista" en el que se establece que la región latinoamericana enfrenta baja integración económica, debilidad en 
lo institucional, laxitud en el manejo de los compromisos y enormes dificultades en relación a problemas internos, nacionales, domésticos y locales que limitan una proyección de poder mancomunada. En este contexto, en términos de cooperación y en temas de concertación frente al regionalismo se ha avanzado, a pesar de las visiones opuestas de integración y multilateralismo que se refleja en los distintos esquemas como la UNASUR y la CELAC (Tokatlian, 2011a). Lo anterior no significa que la cooperación regional no se lleva a cabo, sino que la puesta en común o delegación de soberanía ya no es una opción (Malamud \& Gardini, 2012) lo que conlleva a que coexistan procesos de concertación como CELAC, ALBA Y UNASUR, y de cooperación económica como la Alianza del Pacífico.

Dentro del escenario de interpretaciones, Gardini (2013) hace referencia a un "regionalismo modular" para explicar la realidad latinoamericana. Plantea una nueva tendencia regional que refleja la gran cantidad de actores y mesas de negociación, y la multiplicación e intersección de temas donde los estados escogen y eligen la membrecía en los proyectos que reflejen sus intereses nacionales y prioridades de política exterior en áreas específicas con un bajo nivel de compromiso. Por lo anterior, se da un retorno de la integración a la cooperación como un instrumento más flexible en temas específicos, manteniendo la soberanía con base en un principio intergubernamental y reflejando la fragmentación actual en América Latina y la preferencia por tratar temas de interés común mediante la preservación de la soberanía nacional.

Dentro de esta realidad, la Alianza del Pacífico resalta su interés regional hacia la convergencia, planteándose "no como un esquema excluyente de otros mecanismos, de otros esquemas de integración regional o subregional sino con el propósito de encontrar áreas de interés común a partir de la necesidad de fortalecer el comercio intrarregional" (RLN, 2014).

Chile ha asumido cierto tipo de liderazgo planteando la convergencia en la diversidad para un acercamiento pragmático entre la Alianza del Pacífico y MERCOSUR, como una cuestión de racionalidad política, 
partiendo de reconocer que la región es diversa y compleja. Para el canciller Heraldo Muñoz, en este escenario "es realismo político reconocer las diferencias, pero sin dejar de buscar convergencias. Porque hay muchos elementos que unen a esta región" (Muñoz, 2015). En conclusión, la Alianza del Pacífico ha buscado plantear bajo la iniciativa de Chile, una convergencia a partir de la cual:

[...] se puede ir construyendo una suerte de arquitectura sobre la base de ladrillos; ladrillos que son las distintas instancias subregionales que van conformando, poco a poco, un edificio regional de integración. He citado a este respecto un concepto acuñado en la Unión Europea: las velocidades diferenciadas o geometría variable, que permite que los países que están en condiciones, y así lo deseen, avancen más rápido que los demás sin perder de vista un horizonte común de largo plazo (Muñoz, 2015, [en línea]).

En cuanto a la Alianza del Pacífico como objeto que percibe, se resalta la necesidad de una mayor integración económica y comercial, a partir de la creencia en común de que el libre tránsito de personas, bienes, servicios y de capital es el instrumento para lograr mayor bienestar e inclusión social para sus ciudadanos de forma conjunta. En este sentido, Michelle Bachelet, Juan Manuel Santos, Enrique Peña Nieto y Ollanta Humala señalan:

Si debemos resaltar una característica de nuestro proceso de integración seria este: creemos firmemente que el principal objetivo de la Alianza del Pacífico es mejorar el bienestar de todos nuestros ciudadanos y promover el crecimiento y desarrollo económico, así como la mejora y la competitividad de nuestras economías. Hace tres años, enfrentamos el reto de como fomentar un proceso que fortaleciera nuestros países, y que especialmente, nos ayudará a construir un puente con la región de Asia Pacífico. Esta aspiración se ha convertido en una realidad. Continuaremos trabajando juntos, como socios, para lograr nuestros objetivos comunes y fortalecer y expandir nuestra visión, para el beneficio de nuestras acciones (Bachelet, Santos, Peña Nieto, \& Humala, 2014, [en línea] s. p.). 
De esta manera, la Alianza del Pacífico se constituye como una entidad geoestratégica, social y cultural, cuya esencia neoliberal propende por el establecimiento de un área de libre comercio orientada hacia la creación de un área de integración profunda dentro de una región heterogénea en construcción.

Institucionalidad. Dentro de este factor se pueden señalar los tres pilares institucionales de la Alianza del Pacífico:

a. La construcción de un área de integración profunda para avanzar progresivamente hacia la libre circulación de bienes, servicios, capitales y personas;

b. Impulsar un mayor crecimiento, desarrollo y competitividad de las economías de las partes, con miras a lograr, un mayor bienestar, la superación de la desigualdad socioeconómica y la inclusión social de sus habitantes; $y$

c. Convertirse en una plataforma de articulación política, de integración comercial, y de proyección al mundo, con especial énfasis al Asia-Pacífico (Acuerdo Marco, 2012, [en línea]).

A su vez, y teniendo en cuenta la definición de multilateralismo presentada en el modelo de análisis, los principios generales de conducta establecidos señalan que entre los requisitos esenciales para la participación en la Alianza del Pacífico se establecen: a) la vigencia del estado de derecho, de la democracia y de los respectivos órdenes constitucionales; b) la separación de los poderes del estado, y, c) la protección, promoción, respeto, garantía de los derechos humanos y las libertades fundamentales (Acuerdo Marco, 2012).

En cuanto a su institucionalidad, dentro del perfil del multilateralismo latinoamericano, la Alianza del Pacífico se encuentra dentro del patrón contemporáneo dado que sus elementos institucionales se caracterizan por, en primera medida, ser estatocéntricos, dado su carácter presidencialista, pro tempore, con énfasis en la promoción de espacios para el diálogo político y la concertación, y su debilidad institucional (Legler, 2010; Legler \& Santa Cruz, 2011). Sin embargo, su proyecto político trasciende de la etapa de concertación desarrollada 
en el marco del Foro sobre la Iniciativa de la Cuenca del Pacifico Latinoamericano, conocida como el Arco del Pacífico, a la configuración de un esquema de cooperación económica con la firma del Acuerdo Marco y su Protocolo Adicional.

En conclusión, la Alianza del Pacifico es una iniciativa intergubernamental en la cual, el proceso de toma de decisiones se lleva a cabo por consenso, contando con la participación del sector empresarial como motor de las relaciones económico-comerciales; además, es necesario resaltar que como régimen internacional no implica un profundo esquema de integración política y económica. La Alianza del Pacífico se configura como un esquema de cooperación económica con trasfondo político, dada la interdependencia política frente a las externalidades negativas de los cambios geopolíticos a nivel regional e internacional, cuyos desafíos se centran en una profundización económica a partir de una débil institucionalidad para una mayor proyección internacional que aumente el poder negociador y que trascienda la característica de un proceso embrionario caracterizado por la suma de las economías nacionales de las partes sin una fuerte interdependencia económica y complementariedad.

\section{Reflexiones finales}

A partir de las categorías de análisis planteadas como factores de éxito en el modelo de análisis propuesto sobre cohesión regional, el proceso de consolidación de la Alianza del Pacífico como actor regional enfrenta grandes debilidades y fortalezas para hacer frente a las oportunidades y amenazas, dadas las trasformaciones del sistema internacional. Así, no existe una clara pretensión de liderazgo para ser ejercido de manera unilateral por uno de los miembros, que implique asumir los costos de la integración (paymaster). En este sentido, los países miembros de la Alianza del Pacífico buscan superar el liderazgo desde una relación estructural de verticalidad desde el supuesto de estabilidad hegemónica como requisito para el éxito, apostando, en cambio, por un nuevo asociacionismo que implique mayor visibilidad en el escenario regional e internacional dentro de las dinámicas sur- 
sur sobre la base de una cooperación económica; sin desconocer las asimetrías en términos de capacidades.

La creación de este nuevo asociacionismo implica una alternativa estratégica para las partes, teniendo en cuenta las propuestas de regionalismo que emergieron en el siglo XXI, catalogándolo como poshegemónico o posliberal, y que determinaron el orden político latinoamericano en el ciclo actual de la dinámica regional, así como la necesidad de una proyección mancomunada desde una región heterogénea en construcción, cuya identidad se ha visto limitada por las posiciones reactivas y defensivas frente a actores y/o amenazas externas y a la falta de consenso y convergencia regional que conlleve a hablar de una América Latina, diversa y heterogénea, pero unida y cohesionada frente a los factores de éxito planteados.

De igual manera, la interdependencia que afrenta como consecuencia de la debilidad de sus relaciones en términos económico-comercial representa un gran reto y oportunidad para el fortalecimiento de los compromisos de las partes hacia cadenas de valor y complementariedad económica mediante la cooperación.

Su convergencia regional no se debe limitar al alineamiento y acoplamiento frente a la potencia hemisférica como exclusivo referente de poder, sino al reconocimiento de la mutidimensionalidad del poder $\mathrm{y}$ las características que consigo ha traído el sistema internacional con la reconfiguración de un nuevo orden mundial, en el que se busque fortalecer la Alianza del Pacífico como actor regional a partir de la viabilidad nacional de sus miembros y la permisibilidad internacional con el actual orden multipolar para reducir sensibilidades y vulnerabilidades .

Por último, en términos de institucionalidad, es indispensable reconocer el avance de los objetivos y logros propuestos a partir del nivel de concertación logrado en el Arco del Pacífico Latinoamérica hacia la creación de un régimen internación en el que convergieron para la creación de un espacio de cooperación económica sobre la base de pilares especialmente económicos con principios generales de conducta políticos. Sin embargo, la principal debilidad se centra en términos de 
la alta dependencia existente a la voluntad política para la continuidad y consolidación del proyecto político regional propuesto a partir de los niveles de concertación y cooperación.

En conclusión, la cohesión regional de la Alianza del Pacífico para una proyección mancomunada como actor regional, determinan la vinculación con Asia-Pacífico a partir de las áreas de oportunidad que representan tanto sus debilidades como sus fortalezas en términos de cohesión regional de acuerdo a las especificidades, dinámicas e intereses. Así, dadas las debilidades y fortalezas en términos de cohesión regional propuestas y desarrolladas en este artículo, cabe la pregunta ¿Cuáles son las amenazas y oportunidades que representa la región Asia-Pacífico para la Alianza del Pacífico como plataforma de inserción internacional y esquema de cooperación económica?

\section{Referencias}

Acuerdo Marco (2012). Recuperado de http:/ /www.tlc.gov.co/publicaciones.php?id $=6357$

ALADI. (2012). Sistema de Información de Comercio Exterior. Recuperado de http:// consultaweb.aladi.org/sicoex/jsf/home.seam?cid=12018

Ardila, M. (2012). Potencia regional secundaria en definición: Colombia entre Sur y Centroamérica. Papel Político, 17(1), 293-319.

Artaza Rouxel, M. (2012). Interés Nacional y Principios de la Política Exterior. En M. Artaza Rouxel \& C. Ross O (Eds.), La política exterior de Chile, 1990-2009. Del aislamiento a la integración global, (primera edición), (pp. 21-50). Santiago de Chile: Ril editores.

Bachelet, M. (2013). Chile para todos. Programa de Gobierno 2014-2018. Recuperado de http:// michellebachelet.cl/programa/

Bachelet, M., Santos, J. M., Peña Nieto, E., \& Humala, O. (2014, septiembre 21). Chile, Colombia, México, Perú: Mejor Juntos. Recuperado de http:// www.direcon.gob.cl/2014/09/chile-colombia-mexico-peru-bettertogether/

Bartesaghi, I., \& Pereira, M. E. (2016). La cohesión regional en los procesos de integración en América Latina y el Caribe. Journal of Tecbnology Management \& Innovation, 11(1), 93-101. 
Briceño Ruiz, J. (2012). La Alianza del Pacífico: la viabilidad de un naciente bloque regional. En M. Ardila (Ed.), El Pacifico latinoamericano y su inserción internacional, (primera edición), (pp. 135-157). Bogotá: Pontificia Universidad Javeriana.

Briceño Ruiz, J. (2013). Ejes y modelos en la etapa actual de la integración económica regional en América Latina. Estudios Internacionales - Universidad de Chile, 45(175), 9-39.

Camargo, S. (2000). Orden mundial, multilateralismo, regionalismo. Perspectivas clásicas y perspectivas críticas. En F. Rojas Aravena (Ed.), Multilateralismo. Perspectivas latinoamericanas, (pp. 55-76). Caracas: Nueva Sociedad.

Cuervo, K. M. (2004). Estudios de convergencia y divergencia regional en América Latina: balance y perspectivas. Investigaciones Regionales, 5(otoño), 29-65.

Del Arenal, C. (2001). La nueva sociedad mundial y las nuevas realidades internacionales: un reto para la teoría y para la política. Cursos de Derecho Internacional y Relaciones Internacionales de Vitoria-Gasteiz, 17-86.

Del Arenal, C. del. (2005). En torno al concepto de sociedad internacional. En J. F. B. Sampaio, V. E. Pérez, C. A. J. Rodríguez, F. A. Salinas, G.-U. M. Vargas \& Carrillo, S. J. A.(Eds.), Soberania del Estado y Derecho Internacional. Homenaje al profesor Juan Antonio Carrillo, (pp. 453-464). Sevilla: Universidad de Córdoba/Universidad de Sevilla/ Universidad de Málaga.

Del Arenal, C. del. (2009). Mundialización, creciente interdependencia y globalización en las Relaciones Internacionales. En Cursos de Derecho Internacional y Relaciones Internacionales de Vitoria-Gasteiz. 2008 (pp. 181 268). Bilbao: Servicio de Publicaciones de la Universidad del País Vasco.

Destradi, S. (2010). Regional Powers and Their Strategies: Empire, Hegemony, and Leadership. Review of International Studies, 36(4), 903-930.

Frasson-Quenoz, F. (2015). Autores y teorias de Relaciones Internacionales: una cartografía. Bogotá: Universidad Externado de Colombia.

Gardini, G. L. (2010). Proyectos de integración regional sudamericana: hacia una teoría de convergencia regional. Relaciones Internacionales, 15, 11-31. Gardini, G. L. (2013). The Added Value of the Pacific Alliance and 'Modular Regionalism' in Latin America. International Affairs at LSE. Recuperado de http://blogs.lse.ac.uk/ideas/2013/06/the-added-value-of-thepacific-alliance-and-modular-regionalism-in-latin-america/ 
González, G. (2008). México en América Latina: entre el norte y el sur o el dificil juego del equilibrista. En R. Lagos (Ed.), América Latina: ¿integración o fragmentación?, (pp. 115-144). Buenos Aires: Edhasa.

Hettne, B. (2002). El nuevo regionalismo y el retorno a lo político. Comercio Exterior, 52(11), 954-965.

Hettne, B., \& Söderbaum, F. (2000). Theorising the Rise of Regionness. New Political Economy, 5(3), 457-473.

Hopf, T. (2002). Social Construction of International Politics: Identities \& Foreign Policies. Moscú: Cornell University Press.

Ibañez, J. (2000). El nuevo regionalismo latinoamericano en los años noventa. Revista Electrónica de Estudios Internacionales, (1), 1-11.

Jaguaribe, H. (1979). Autonomía periférica y hegemonía céntrica. Estudios Internacionales, 12(46), 91-130.

Keohane, R. (1993). Institucionalismo Neoliberal: Una perspectiva de la Política Mundial. En C. Piña (Trad.), Instituciones internacionales y poder estatal: ensayos sobre teoría de las relaciones internacionales, (pp. 13-38). Buenos Aires: Grupo Editor Latinoamericano.

Keohane, R., \& Nye, J. (1977). Power and Interdependence: World Politics in Transition. Boston: Little Brown.

Kiselev, I. Y., \& Smirnova, A. (2004). La dinámica de la autoimagen de los Estados Unidos a través de los discursos públicos. Psicología Política, (28), 55-68.

Kubálková, V. (2001). Foreign Policy, International Politics, and Constructivism. En V. Kubálková (Ed.), Foreign Policy in a Constructed World (pp. 15-37). Armonk, N.Y.: M.E. Sharpe.

Legler, T. (2010). El perfil del multilateralismo latinoamericano. Foreign Affairs Latinoamérica, 10(3), 2-5.

Legler, T., \& Santa Cruz, A. (Eds.). (2011). El patrón contemporáneo del multilateralismo latinoamericano. En Los desafíos del multilateralismo en América Latina Vol. 16 (pp. 11-34). Argentina: Pensamiento Propio. CRIES-UNIVERSIDAD DE GUADALAJARA-UNIVERSIDAD IBEROAMERICANA.

Malamud, A. (2011). A Leader without Followers? The Growing Divergence Between the Regional and Global Performance of Brazilian Foreign Policy. Latin American Politics and Society, 53(3), 1-24. 
Malamud, A., \& Gardini, G. L. (2012). Has Regionalism Peaked? The Latin American Quagmire and its Lessons. The International Spectator: Italian Journal of International Affairs, 47(1), 116-133.

Moravcsik, A. (1998). The Choice for Europe: Social Purpose and State Power from Messina to Maastricht (primera edición). New York: Cornell University Press.

Moravcsik, A. (2008). The New Liberalism. En C. Reus-Smith \& D. Snidal (Eds.), The Oxford Handbook of International Relations (pp. 234-254). New York: Oxford University Press.

Muñoz, H. (2015). Clase Magistral de Canciller Heraldo Muñoz: Los Retos de la Política Exterior. Recuperado de http:/ / www.apuntesinternacionales.cl/clase-magistral-del-canciller-heraldo-munoz-en-la-universidadcatolica-los-retos-de-la-politica-exterior/

Nolte, D. (2006). Potencias regionales en la política internacional: conceptos y enfoques de análisis. GIGA Working Papers, 30, 1-37.

OMC. (2013). Perfiles Comerciales 2013. Suiza: Organización Mundial del Comercio. Recuperado de http://www.wto.org/spanish/res_s/ booksp_s/trade_profiles13_s.pdf

RLN. (2014, septiembre 23). Mandataria destacó crecimiento de la Alianza del Pacífico. RLN. Recuperado de rln.cl/nacional/8803-mandatariadestaco-crecimiento-de-la-alianza-del-pacifico.html

Ruggie, J. G. (1998). Constructing the World Polity: Essays on International Institutionalization. London ; New York: Routledge.

Serrano, L. O. (2008). Sobre la naturaleza de la integración regional: teorías y debates. Revista de Ciencia Política, 28(2), 95-113.

Söderbaum, F. (2003). Introduction: Theories of New Regionalism. En F. Söderbaum (Ed.), Theories of New Regionalism (pp. 1-21). Basingstoke: Palgrave: A Palgrave Macmillan Reader.

Soriano, J. P. (2012). Dilma y México: altibajos en una relación indispensable para América Latina. Revista CIDOB d'afers internacionals, (97-98), 135-149.

Tickner, A. (2002). Los estudios internacionales en América Latina: ¿subordinacion intelectual o pensamiento emancipatorio? (Primera edición). Bogotá: Universidad de los Andes, CESO, Departamento de Ciencia Política: Alfaomega Colombiana. 
Tokatlian, J. (1994). Componentes políticos de la integración. En Integracion, desarrollo económico y competitividad, (pp. 49-58). Bogotá: Centro Regional de Estudios del Tercer Mundo, CRE-SET.

Tokatlian, J. (2011a). Latinoamérica y sus opciones estratégicas: un análisis de las relaciones extra-regionales. Análisis Político, 73, 139-158.

Tokatlian, J. (2011b). Política Exterior: un reordenamiento de América Latina. Centro de Pensamiento Estratégico -Ministerio de Relaciones Exteriores. Recuperado de http://www.cancilleria.gov.co/sites/default/files/pensamiento_estrategico/documentos_sobre_region/a.Politica $\% 20$ Exterior, $\% 20 \mathrm{Un} \% 20$ Reordenamiento $\% 20$ en $\% 20$ America $\% 20$ Latina $\% 20$ -\%20Julio\%202012\%20-\%20Juan\%20TOKATLIAN.pdf

Tokatlian, J., \& Russell, R. (2009). Modelos de política exterior y opciones estratégicas. El caso de América Latina frente a Estados Unidos. Revista Cidob d'afers Internacionals, (85-86), 211-249.

Torres del Sel, M. M. (2013). Las Políticas regionales de México, Brasil y Venezuela con respecto a la integración de América Latina. Invenio: Revista de investigación académica, (30), 29-46.

Van Klaveren, A. (2011). La Política exterior de Chile durante los gobiernos de la Concertación. Estudios Internacionales. Instituto de Estudios Internacionales - Universidad de Chile, (169), 155-172.

Villamar, Z. (2013). La política exterior mexicana tras el regreso del PRI. Una visión para los próximos seis años. Nueva Sociedad, (247), 16-26. 